Send your letters to the Editor,

British Dental Journal,

64 Wimpole Street

London

W1G 8YS

E-mailbdj@bda.org

Priority will be given to letters less than 500 words long.

Authors must sign the letter, which

may be edited for reasons of space.

\section{COMMUNICATION FAILURE}

Sir, I appreciate the innovation shown by R. Huang (Tooth surface recording; BDJ $2008 ; 204: 5)$. The system surely is good but at the same time is quite confusing. I would find it difficult to communicate to my colleagues using such a system, for example if I need to communicate or record a grossly decayed permanent mandibular first molar of the left side which has only the distal wall which is not involved, then I will have to designate it as 361235 , which makes it a difficult task to actually correlate the six digit number with the walls involved by carious lesion. Similarly, in the case of two or more teeth involved with caries on more than one aspect for example 112, 37124, 47125, 36245 , the trouble of communication will further increase. Also the system does not denote the severity of the lesion and has no criterion for root surface caries.

The refined system denoting the symbols poses the same problem of communication. However, it is a better idea to use this system on paper. Some standardisation will still be needed in this refined system. The author did not mention on which side (towards the midline or away from the midline) of the quadrant chart one should mention the symbols. The symbols for labial, lingual, mesial and distal are mentioned near the midline ie towards the mesial side. But the symbol for occlusal caries has been written on the distal side. One may write all the symbols on the mesial side and others may use the distal side for the same. If the method is made more standardised, it will be useful for recording the tooth surfaces but communication will still fail.

M. Juneja

Lucknow

DOI: 10.1038/sj.bdj.2008.253

\section{BREAST IS BEST}

Sir, we are writing to share best practice with your readers and invite them to help us support more mothers to breastfeed.

Babies who are formula fed are at significant disadvantage with regards to short and long term illness, including infections, diabetes and allergy. Breastfeeding mothers are also at a lower risk of long term health conditions including female cancers and osteoporosis. The DH recommends babies be exclusively breastfed for six months, and then receive breast milk alongside solid foods for at least 12 months. The World Health Organisation urges mothers to breastfeed for at least two years, based on evidence of benefit to the health of mother and child.

Despite this there have been concerns that long term breastfeeding could contribute to dental caries in the baby, and this has been reflected in advice from some dentists and dental health organisations to limit breastfeeding frequency and duration. For example, the website of the British Dental Health Foundation recommends that babies are weaned from breastfeeding at around six months to prevent dental caries.

This concern is based on case reports from two small studies which were reported in the 1970s. ${ }^{1,2}$ In these cases, all nine children presented with caries and had been breastfed for over one year, and at night. A causal association was found by the authors, which prompted advice to parents to cease breastfeeding once the teeth erupt.

More recent research has demonstrated a positive association between breastfeeding and dental health. Among breastfed children, the longer the duration of breastfeeding, the lower the incidence of malocclusion. ${ }^{3}$ Also, children who have been breastfed show fewer decayed deciduous teeth than children not breastfed, ${ }^{4}$ which appears to contradict the earlier findings. The main risk associated with nursing caries in breastfed infants appears to be deficiency in the dental enamel, and this is coincidental to long term breastfeeding.

The mechanism of breastfeeding appears to protect the teeth against caries. Breast milk itself is protective against Streptococcus mutans. During breastfeeding, the milk is ejected into the rear of the oral cavity, and does not pool around the front teeth as occurs with a bottle. A study by Irish dentist Harry Torney found no association between long term on demand breastfeeding and dental caries. ${ }^{5}$

Parents require information about oral hygiene and dietary advice in order to reduce the risk of dental caries and those who have a family history of caries in infancy should be advised to register their baby with a dentist for early evaluation once the teeth have erupted. All family members should be encouraged in good oral hygiene during the pregnancy to avoid transfer of $S$. mutans. These factors are significant in reducing the risks in breastfed infants. For those parents who are bottle feeding, attention should be paid to ensuring the use of the bottle is for short periods, and only with milk. We would encourage parents to offer milk and water from cups from around six months.

Given the benefits for dental health, and the lack of any evidence of harm of long term breastfeeding, we call for our dental colleagues to support the DH and WHO recommendations 
and ensure parents are supported to breastfeed their infants for as long as they wish.

\section{A. Cartwright}

On behalf of the West Midlands Breastfeeding Specialist Group

1. Gardner D E, Norwood J R, Eisenson J E. At will breastfeeding and dental caries: four case reports. ASDC J Dent Child 1977; 44: 186-191.

2. Kotlow L A. Breastfeeding: a cause of dental caries in children. ASDC J Dent Child 1977; 44: 192-193.

3. Labbok M H, Hendershot G E. Does breastfeeding protect against malocclusion? An analysis of the 1981 child health supplement of the National Health Interview Survey. Am J Prev Med 1987; 3: 227-232

4. Buhl M etal. Epidemiologic findings concerning the incidence of caries in the deciduous dentition of infants. Dtsch Zahnarztl Z 1986; 41: 1038-1042.

5. Torney H. Prolonged, on-demand breastfeeding and dental caries - an investigation [unpublished MDS thesis]. Dublin, Ireland, 1992.

DOI: 10.1038/sj.bdj.2008.254

\section{INFORMED CONSENT}

Sir, I am a dental patient and a junior doctor. On a daily basis in my job, I help patients make informed decisions about investigations and treatment. Over the past two years I've had several visits to different dentists following root canal treatment when an instrument was fractured in the root of the tooth. This has now resulted in me having the tooth extracted and I am awaiting implant treatment. These events have sadly made me lose confidence in the dental profession. I do not feel that any clinical error has been made. In fact, I would completely understand what has happened if only I had been made aware that these complications could occur. Patients have the right to refuse or consent to treatment and need to have enough information to help make that decision. Without informing patients of potential complications, dentists leave themselves open to complaints. Guidance on patient consent has been produced by the General Dental Council. ${ }^{1}$ This states that for consent to be valid a patient must have received enough information to make a decision. The following information is suggested:

- Why you think a proposed treatment is necessary

- Risks and benefits of the proposed treatment

- What might happen if the treatment is not carried out

- Alternative treatments.
Not once were the risks of a root canal described to me. After realising the instrument had been fractured, I was simply prescribed antibiotics and discharged without being informed about any possible repercussions. I waited 18 months thinking I was just imagining the pain I was experiencing before finally consulting a different dentist to be told there was an abscess at the base of the root. Once again, no information was given to me about the possible complications of an extraction. One might argue that if I did not have the root canal treatment I would have lost the tooth anyway, therefore the dentist was acting on the ethical principle of beneficence. That would be like offering a patient sightsaving cataract surgery and not telling them about the rare possibility of blindness as a complication of the operation. We must respect patients' autonomy; it is our moral and legal obligation to ensure patients are adequately informed before consenting to treatment. By notifying patients of potential problems, they will be better prepared to deal with them if they arise and will not lose confidence in the ability of the professionals who treat them.

\section{F. Speirs \\ Newcastle-upon-Tyne}

1. General Dental Council. Principles of patient consent, May 2005. http://www.gdc-uk.org/NR/ rdonlyres/6F3D848E-F31A-4A8C-AEFA-C4D78D06 B618/16688/147163_Patient_Cons.pdf Accessed 9 February 2008.

DOI: 10.1038/sj.bdj.2008.255

\section{HIGH SPEED LACERATION}

Sir, I would like to share with your readers an unusual complication of dental treatment using high speed rotary instruments.

Some of the more commonly known complications resulting from the use of rotary instruments during dental treatment include burns, lacerations, surgical emphysema and amalgam tattooing. We encountered an unusual soft tissue complication which resulted in the thrombosis and simultaneous avulsion of a sublingual vein.

A 45-year-old gentleman with no relevant medical history attended his dental practice for a restoration of a lower premolar tooth. Following the administration of a local anaesthetic, cavity preparation was carried out using a diamond bur held in a high speed handpiece.

During this procedure the rotating bur made contact with the floor of the mouth resulting in the traumatic lesion pictured. The general dental practitioner (GDP) referred the patient to the oral and maxillofacial surgery department. There was no bleeding from the site but the GDP was concerned about the unusual thread-like appearance of the traumatic lesion. On examination there was a thread-like structure protruding from a straight, $2 \mathrm{~cm}$ laceration in the mucosa overlying the floor of mouth (Figs 1-2).

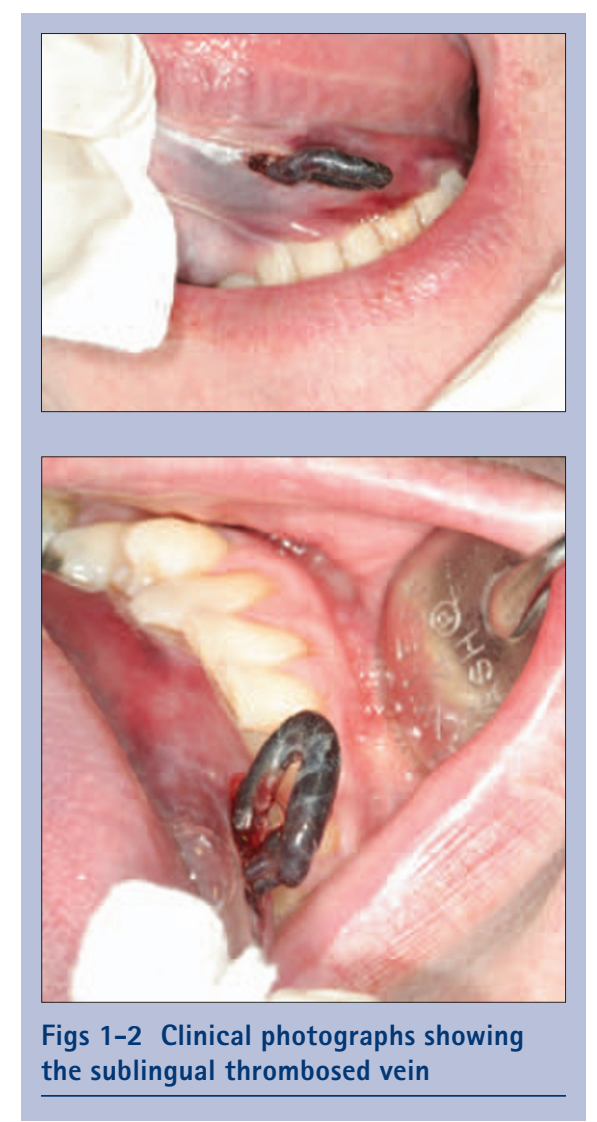

It was deduced that the high speed handpiece had lacerated the floor of the mouth and caused simultaneous avulsion and thrombosis of a sublingual vein.

The avulsed portion of the vessel was ligated and excised. The patient was given prophylactic antibiotics. Histology confirmed a thrombosed vessel. On review the area had healed completely.

J. Dhanda

M. Thomas

A. Kheraj

By email

DOI: $10.1038 /$ sj.bdj.2008.256 


\section{TONGUE LACERATIONS}

Sir, at present there is conflicting literature regarding the appropriate management of tongue lacerations. Recommendations include suturing injuries located on the dorsum and lateral borders, ${ }^{1}$ those that are greater than $2 \mathrm{~cm}$ in length or when haemostasis has not been achieved. ${ }^{2}$ Deep tongue lacerations should be sutured in layers using resorbable sutures, ${ }^{3}$ and before excessive oedema occurs, ie within eight hours of injury, as delaying treatment beyond 24 hours would adversely affect the outcome. ${ }^{4}$

Lamell et $a .^{5}$ recommend suturing tongue lacerations if they are gaping at rest, or if they involve the lateral border or if there is active haemorrhaging. He noted on examination that many of the tongue lacerations had well-approximated margins which stopped haemorrhaging, suggesting these injuries to be self-limiting. The application of pressure, cold and inactivity would also help achieve haemostasis.

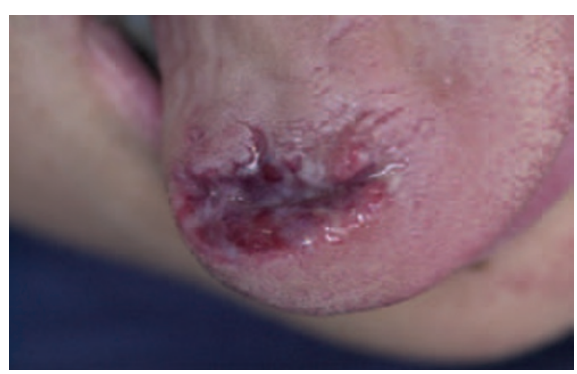

Fig. 1 Initial assessment: a gaping tongue laceration on the dorsal surface

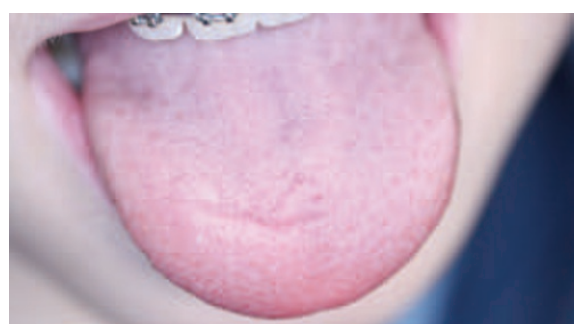

Fig. 2 Review appointment: excellent healing of the tongue with evidence of a minor scar

I would like to describe a patient who suffered a gaping tongue laceration.

An 11-year-old child attended the Royal London Hospital emergency department shortly after falling onto concrete whilst playing football. He was managed conservatively and referred to the children's dental emergency clinic for a dental assessment the following day.
On extra-oral examination the patient had a swollen upper lip and superficial abrasions on his chin. Intra-orally, he had upper and lower fixed orthodontic appliances with gingival tearing palatal to the upper incisors. The occlusion was undisturbed and no fractures were noted on the teeth. He had a tongue laceration on the dorsal surface of the tongue which was $3.5 \mathrm{~cm}$ in length and gaping $1 \mathrm{~cm}$ at rest. This laceration had been treated conservatively. It had stopped bleeding on examination.

Special investigations on the upper incisors revealed a negative vitality test to ethyl chloride with no tenderness to percussion. Radiographic examination revealed no abnormalities. The patient was diagnosed with concussion relative to the upper central and lateral incisors and a lacerated tongue, which were both managed conservatively.

At the review appointment the patient had no complaints. The abrasions had healed and there were no changes to the dentition. The tongue healed extremely well with evidence of a minor scar. The upper incisors tested positively to thermal vitality testing.

This case highlights the need for careful assessment of tongue lacerations and leads to the question 'to suture or not to suture?' According to the criteria mentioned the tongue laceration should have been sutured as it was 'gaping at rest'. However, the examining clinician felt it was best not to suture this wound, and the photograph at the review appointment clearly shows excellent healing with minimal scarring. It is fair to say that clinicians should not be in a hurry to suture wounds as doing so does not improve the outcome nor reduce the morbidity associated with this type of injury. In particular to young children, behaviour management needs to be seriously considered as sedation or general anaesthesia may be required to place sutures.

A. Patel London

1. Andreasen J 0, Andreasen F M. Textbook and colour atlas of traumatic injuries to the teeth. pp 511-514. Mosby Year Book, 1994.

2. Donat T L, Maisel R H, Mathog R H. Injuries to the mouth, pharynx and oesophagus. Paediatric otolaryngology, 3rd ed. pp 1183-1184. WB Saunders, 1996.

3. Powers M P, Bertz J, Fonseca R J. Management of soft tissue injuries. Oral and maxillofacial trauma. pp 616-648. WB Saunders, 1991

4. Banks P, Brown A. Fractures of the facial skeleton. p 29. Wright, 2002

5. Lamell C W, Fraone G et al. Presenting characteristics and treatment outcomes for tongue lacerations in children. Pediatr Dent 1999; 21: 34-38.

\section{DOI: 10.1038/sj.bdj.2008.257}

\section{MICRO-IMPLANTS}

Sir, I write further to the paper on developmentally absent maxillary lateral incisors (BDJ 2007; 203: 654).

Until recently I would have resorted to one of the two conventional treatment options in the management of missing lateral incisors however, today, my orthodontic practice has taken a different dimension with the introduction of micro-implants. I would wholeheartedly prefer to close the space by buccal segment protraction using micro-implants and negate the use of any prosthodontic fixtures, thus reducing the liabilities on the patient's part for a long term commitment. The versatility of the use of micro-implants should not be over emphasised but most clinical orthodontic problems would be solved at minimal cost and time as compared to the interdisciplinary care (restorative options).

A. Sivakumar

A. Valiathan Manipal DOI: 10.1038/sj.bdj.2008.258

\section{COURAGEOUS DECISION}

Sir, it is pleasing to see that due prominence is given to the important article Conscious sedation for dentistry: an update not only in this Journal ( $B D J$ 2007; 203: 624) but also in the Royal College of Anaesthetists Bulletin (January 2008 issue 47: 2405).

However, the authors in their 'Background' fail to record the courageous decision taken, within the dental profession, to restrict the use of general anaesthesia in dental practice. This restriction was aimed to provide greater protection to the public, particularly as there had been an escalating number of tragic deaths of patients receiving dental treatment under GA.

The new ethical guidance adopted unanimously at the 10 November 1998 meeting of the General Dental Council was implemented immediately which meant that only specified anaesthetists were permitted to administer GA as well as ensuring 
that the correct procedures were in place for monitoring and resuscitating patients. Throughout formulating and activating the new guidance the close collaboration with the RCA and in particular the support and advice from its President, Professor Leo Strunin and Professor Tony Wildsmith, should not be forgotten.

In 1998 it was also made clear by the GDC review group on Resuscitation, Sedation and GA in Dentistry that urgent steps were needed to safeguard within the profession the teaching and practices of sedation and pain control. The present authors are to be congratulated on returning to this theme. It would indeed be a sad day for patients if sedation was not permitted to be delivered within the confines of a dental practice.

D. Pike, Colchester

M. Seward, Bournemouth DOI: 10.1038/sj.bdj.2008.259

\section{SAS CONTRACT}

Sir, I write with concern regarding the proposals for the new SAS contract, in particular how they are likely to affect a large number of dentally qualified SAS grades in Oral and Maxillofacial Surgery. I do not feel it has been made clear enough that the new contract means that they will get paid substantially less for their on call. They will only be paid between 2-6\% of their basic salary for being on call, and time and a third for the time they are working.

SAS grades are often on call day and night for complex problems relating to airway compromise, severe dental infections and post operative ward patients. I feel that being paid around $£ 7$ an hour for this is an insult. The new contract also offers a $25 \%$ pay reduction for the top salary in the new grade. In addition normal working hours are now regarded as between $7 \mathrm{am}-7 \mathrm{pm}$. The small pay increase of our basic pay is not really an increase as the number of programmed hours has also increased.

I feel that it is important SAS grades in Oral and Maxillofacial Surgery understand the new contract. I would therefore urge all SAS grades to ensure they are registered to vote by adding their details via the $B D J$ website and vote against the new contract proposals when the forms are posted out. Further details of the contract can be accessed on the BMA website. They may also like to join the new National Staff and Associate Specialists Group (www.nsasg.org.uk) that has been set up by SAS grades for SAS grades.

A. Geddes, Gateshead Joint Secretary NSASG

DOI: $10.1038 /$ sj.bdj.2008.260

\section{AESTHETIC OPTIONS}

Sir, I've just been looking at a case report published in one of the dental periodicals illustrating the provision of eight veneers on the upper labial segment. I understand the demand for this type of treatment is increasing exponentially and a good aesthetic result can be achieved in a short time. Even though the use of veneers is less invasive than for conventional crown preps a substantial amount of tooth substance was removed in the case report to make the final result appear well aligned. The original teeth were of good colour and morphology. As an orthodontist I wondered if the patient was aware that these teeth could have been aligned in less than six months with, for example, lingual braces or clear aligners with no need to prep the teeth? The aesthetic dentistry market is undoubtedly competitive but it is still incumbent upon both orthodontists and their restorative counterparts to ensure patients are given all their options before consent can be viewed as truly informed.

N. Henderson By email

DOI: 10.1038/sj.bdj.2008.261

\section{RECIPE FOR CONFUSION}

Sir, while socio-demographics are an important consideration for the BDA, as detailed in Dr Ward's editorial (BDJ 2008; 204: 1), I wonder if economic circumstance might not be as equally important when designing the services provided and committee composition of the Association. It appears to me that there is a growing chasm between the considerations and support needs of those members working within the health service and private practice.

To run a successful business with a PCT contract places a series of operational imperatives on practice owners and managers. Considering that return on investment and profitability will be driven by the way a practice responds to the rules negotiated with a single customer (PCT), and that each of the PCTs does not behave identically, are the members well equipped to plan their business into the future? Is the diversity of contract terms being charted and are these members being supported appropriately?

Private practice has a completely different set of business and economic rules driven by the market in which it operates. Many private practices are pushing to expand their service offering into cosmetic dentistry and even facial aesthetics. While good quality preventative oral health care remains the backbone of these cosmetic practices it is difficult to imagine a larger gap between the business strategies of a cosmetic practice and a full NHS one.

With a majority of practices trying to operate PCT contracts and private services within the same building using the same staff (both clinical and support), is this not a recipe for confusion and poor business achievement leading to increased stress and declining clinical standards?

D. Holland

By email

DOI: $10.1038 /$ sj.bdj.2008.262

\section{PIGEON-HOLING}

Sir, with reference to Peter Ward's editorial (BDJ 2008; 204: 1), put quite bluntly, the racial pigeon-holing that is in vogue is extremely divisive and offensive. For example, we do not need a Black/Jewish/ Gay police officers' association. There just needs to be just one for all.

The best have to be picked for the job, not chosen to make up the numbers as that means a reduction in standards.

I and everybody need to know that when a life-saving operation is to be performed, the black/Asian/white/gay/ oriental etc surgeon that is standing over us is there on merit alone.

For the record, I am in one of the smallest 'ethnic' groups in the country, being one of 300,000. I am also half Iranian, one quarter Russian and one quarter Polish and I flatly refuse to fill in any ethnic origin details.

\section{G. Simmons} By email

DOI: $10.1038 /$ sj.bdj.2008.263 